\title{
CONCERNING THE NATURALLY OCCURRING PORPHYRINS
}

\author{
III. The Isolation of Coproporphyrin I from the Feces of Untreated \\ Cases of Pernicious Anemia ${ }^{1}$ \\ By CECIL JAMES WATSON \\ (From the Department of Medicine, Unizersity of Minnesota Hospital, Minneapolis)
}

(Received for publication September 10, 1934)

H. Fischer and Zerweck (9) were the first to recognize the increased urinary excretion of coproporphyrin in cases of pernicious anemia during relapse. Traces of coproporphyrin occur regularly in the normal urine and evidence was presented in Part I of this communication which strongly suggests that the normal urine porphyrin is coproporphyrin I. There is no evidence that this is formed in the bone marrow of the normal individual, rather, the studies of Borst and Königsdörffer (29) are against this view. Van den Bergh's experimental evidence suggesting that coproporphyrin may be formed in the liver has been discussed in Part II. Recently coproporphyrin has been identified in the erythroblasts and megaloblasts of pernicious anemia marrow by Borst and Königsdörffer (29). The reason for this formation of coproporphyrin in the marrow is unknown. Duesberg (23) has assumed it to be simply another evidence of reversion of the pernicious anemia marrow to an embryonic type, since the erythroblasts of normal embryonic marrow regularly contain coproporphyrin according to Borst and Königsdörffer (29), and since coproporphyrin is regularly present in meconium, Garrod (11), Gïnther (12). On the other hand, $\mathrm{H}$. Fischer and Hilmer (30) were able to isolate coproporphyrin I from ordinary brewer's yeast, the amount being greatly increased after autolysis. It was conceivable that the marrow cells in pernicious anemia were to be regarded as cells laboring under abnormal or deficient living conditions, the coproporphyrin being formed for an unknown function in the same way that the yeast cell forms it under abnormal conditions. A further possibility was that the coproporphyrin excreted in pernicious anemia corresponded to aetioporphyrin III, in other words, to hemoglobin, as Grotepass

\footnotetext{
1 Aided by a grant from research funds of the Graduate School of the University of Minnesota.
}

(7) has recently shown to be the case in lead poisoning. Definite knowledge as to the type of coproporphyrin excreted in pernicious anemia is necessary. The amounts in the urine have been too small to permit of its isolation from that source. In 1932, the writer reported the isolation of a coproporphyrin from the feces of a pernicious anemia patient (24). The amount was so small that sufficient recrystallization was not possible; nevertheless, the ester melted at $220^{\circ}$, high enough to preclude the possibility of its being coproporphyrin III. In the present investigation, feces from normal individuals, from individuals suffering from secondary anemias, and from pernicious anemia patients were investigated as to their porphyrin content.

\section{MATERIAL AND METHODS}

The method used for the isolation of the porphyrins from the feces was that described in Part II.

Feces from two cases of pernicious anemia were investigated. The clinical findings in these are briefly described as follows:

Case 1. Female, aged 51. The principal symptoms were weakness, sore tongue, and paresthesias. The stomach contents did not contain free $\mathrm{HCl}$. The hemoglobin was 31 per cent (Sahli), erythrocytes $1,000,000$, leukocytes 2,050, 64 per cent lymphocytes. Stained smears showed marked macro-anisocytosis, poikilocytosis, occasional basophilic stippling and multiple nuclear buds. Reticulocytes 2.4 per cent. Following intramuscular liver therapy the reticulocyte count increased to 12.1 per cent with progressive increase of hemoglobin and erythrocytes, and marked improvement in condition.

The entire amount of feces for an eight day period prior to liver therapy was subjected to the procedure described in Part II. The patient was seen again ten months later. The hemoglobin 
was now 80 per cent (Sahli), the erythrocytes $3,840,000$. The feces for a like period were again examined in the same way as to porphyrin content.

Case 2. Female, aged 60. Pale yellow skin, weakness, and sore tongue of six months duration. Hemoglobin 25 per cent, erythrocytes 900,000, reticulocytes 0.5 per cent, leukocytes $2,100,74$ per cent lymphocytes. Marked macro-anisocytosis, and poikilocytosis. Some basophilic stippling, occasional normoblasts. The entire amount of feces for six days was subjected to the method of isolation.

The feces from six individuals not having pernicious anemia were examined in the same way for the sake of comparison. Two were normal male adults. The collection of feces from both of these covered an eight day period. The other four were hospital patients. One had a high grade anemia secondary to a bleeding duodenal ulcer. The collection of feces from this case covered a period of nine days. Two of the patients had macrocytic anemias, one in association with cirrhosis of the liver, the other with tuberculous lymphadenitis and probable tuberculosis of the spleen. The feces from the former were collected for six days, those of the latter for eight. One patient had the typical symptoms and findings of chronic idiopathic hypochromic anemia, including sore tongue, dysphagia, hypochlorhydria, koilonychia, and color index 0.54. The period of collection of feces was eight days. All these individuals were on a general diet with exception of the patient with the bleeding ulcer, who received only milk.

Spectroscopic studies were made with a Zeiss spectrometer of grating type with a comparison prism permitting the absorption spectra of two solutions to be superimposed. For the purpose of spectroscopic study, small amounts of the esters of the porphyrins isolated were saponified in 25 per cent $\mathrm{HCl}$. The absorption spectra of the free porphyrins were then measured, both in 25 per cent $\mathrm{HCl}$, and in ether and acetic solution. They were also directly compared with those of known porphyrins, in the same solvents, by superimposition of their spectra.

\section{RESULTS}

Coproporphyrin I was isolated in the form of its crystalline methyl ester from the feces of both of the cases of pernicious anemia. The amount obtained from the first case after three recrystallizations was approximately $1 \mathrm{mgm}$., from the second $0.6 \mathrm{mgm}$. The melting point of that from the first case was 245 to $247^{\circ} \mathrm{C}$. and from the second 243 to $245^{\circ} \mathrm{C}$. In neither was there any depression of the melting point of a mixture with known coproporphyrin I which melted at 245 to $246^{\circ} \mathrm{C}$.

The absorption spectrum of the porphyrin from the first case in ether and acetic was as follows: I $624.5 \mathrm{~m} \mu$ to 620.8 , maximum $623.1 \mathrm{~m} \mu$, II maximum $566.9 \mathrm{~m} \mu$, III $531.1 \mathrm{~m} \mu$ to 523.9 , maximum $528.5 \mathrm{~m} \mu$, IV $505.0 \mathrm{~m} \mu$ to 489.0 , maximum 496.2 $\mathrm{m} \mu$. Order of intensity: IV, I, III, II.

The absorption spectrum of the second in ether and acetic was: I $624.6 \mathrm{~m} \mu$ to 621.9 , maximum $623.3 \mathrm{~m} \mu$, II faint maximum $567.8 \mathrm{~m} \mu$, III 532.4 $\mathrm{m} \mu$ to 524.4 , maximum $529.1 \mathrm{~m} \mu$, IV $505.6 \mathrm{~m} \mu$ to 488.2 , maximum $496.4 \mathrm{~m} \mu$. Order of intensity: IV, I, III, II. In 25 per cent $\mathrm{HCl}$ : I 596.4 $\mathrm{m} \mu$ to 591.1, maximum $593.4 \mathrm{~m} \mu$, II faint maximum $573.0 \mathrm{~m} \mu$, III $557.5 \mathrm{~m} \mu$ to 544.8 , maximum $551.8 \mathrm{~m} \mu$. Order of intensity : III, I, II.

Feces from the first case, studied ten months after liver therapy had induced a remission, contained so very little coproporphyrin that it could not be obtained in crystalline form. A chloroform soluble porphyrin was present in small amount. This left 0.2 per cent $\mathrm{HCl}$ for chloroform, and gave an insoluble sodium salt, characteristics of a deuteroporphyrin. The amount after three recrystallizations was approximately 0.3 mgm. The crystals (Figure 1) of its methyl ester were like those of the ester of deuteroporphyrin III previously isolated (24). However, the melting point of these crystals was 189 to $191^{\circ} \mathrm{C}$. Deuteroporphyrin III methyl ester melts at $221^{\circ} \mathrm{C}$. A mixture melted at 186 to $189^{\circ} \mathrm{C}$. Surprisingly enough, the absorption spectrum of this porphyrin was practically identical with that of coproporphyrin. In acetic and ether solution the absorption was as follows: I $624.9 \mathrm{~m} \mu$ to 622.9, maximum $623.6 \mathrm{~m} \mu$, II faint at maximum $606.1 \mathrm{~m} \mu$, III $580.8 \mathrm{~m} \mu$ to 566.8 , maximum 568.2 


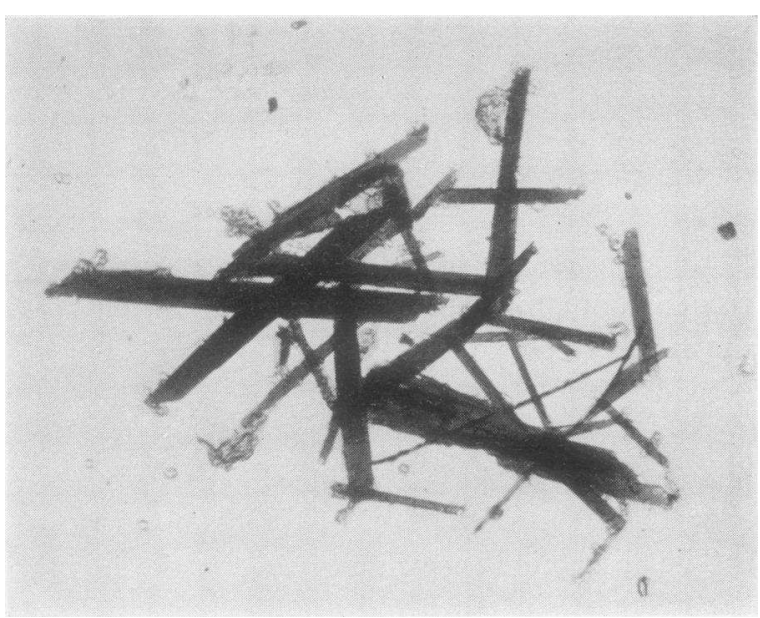

Fig. 1. Crystal.s of the Porphyrin Ester from the Feces in Case 1.

$\mathrm{m} \mu$, IV $533.7 \mathrm{~m} \mu$ to 523.6, maximum $528.9 \mathrm{~m} \mu$, $\mathrm{V} 504.8 \mathrm{~m} \mu$ to 484.9 , maximum $496.1 \mathrm{~m} \mu$. Order of intensity: V, I, IV, III, II. The spectrum was further compared with that of the new porphyrin described in Part II, and found to differ. It is possible that this is the same porphyrin as that obtained repeatedly by $\mathrm{H}$. Fischer and Duesberg (5) from the feces of rabbits. The ester melting point of the porphyrin described by them varied between $182^{\circ}$ and $187^{\circ} \mathrm{C}$. Its absorption spectrum was evidently more nearly that of a deuteroporphyrin than in the present instance, and the authors believed it to be either an impure deuteroporphyrin III, or an isomer. The same may be true of the porphyrin described above. In the absence of positive identification, nothing can be said of its possible significance. The amounts of coproporphyrin from the feces of the six control individuals were in every instance too small to permit of isolation in crystalline form. The amount was smallest from the cases of idiopathic hypochromic anemia, and the secondary anemia with the bleeding ulcer. In the latter case considerable protoporphyrin and a small amount of deuteroporphyrin were demonstrated spectroscopi- cally, as was to be expected following hemorrhage into the gastro-intestinal tract. The new porphyrin described in Part II was not observed in any instance.

\section{COMMENT}

Kämmerer (10) has recently pointed out that because many of the common foods contain traces of coproporphyrin, conclusions based upon finding it in the feces would have to be guarded. There is little doubt that exogenous traces of coproporphyrin occur in all feces; nevertheless, that it was in sufficient amount in the feces of two pernicious anemia patients to be readily isolated in crystalline form, while this was not possible in one of the same cases after liver had induced a remission, nor in six other control cases, was considered significant. Furthermore, the fact that only coproporphyrin I was isolated from the pernicious anemia cases is believed to indicate that the coproporphyrin which $\mathrm{H}$. Fischer and Zerweck (9), and Borst and Königsdörffer (29) have noted in the urine and marrow in pernicious anemia is coproporphyrin I, whose formation from a chemical standpoint has no direct relation to the formation or destruction of hemoglobin, but must be regarded as occurring because of independent synthesis, for reasons as yet unknown.

\section{SUMMARY}

Coproporphyrin I has been isolated from the feces of two typical cases of pernicious anemia during relapse and has been identified by virtue of ester melting point and absorption spectrum. In one of these, studied again after liver had induced a remission, the amount was obviously decreased and too small to isolate. In similar amounts of feces from two normal individuals, and four with anemias of other type, the amounts were too small to permit of isolation.

\section{BIBLIOGRAPHY}

See this issue, page 109. 